\title{
Environmental harmony and the architecture of 'place' in Yoruba urbanism
}

\author{
T. Adejumo ${ }^{1} \&$ M. Adebamowo ${ }^{2}$ \\ ${ }^{I}$ Department of Urban Planning, University of Lagos, Nigeria \\ ${ }^{2}$ Department of Architecture, University of Lagos, Nigeria
}

\begin{abstract}
Harmony in built environment is based on wholeness with nature through a continuous flow of interactions between values and city form. Wholeness accommodates biomimetic principles that link the natural world to the people in a specific 'place'. Biomimicry looks beyond imitating form and process in ecosystem to include world view that solves built environment problems and gives meaning to people in a particular 'place'. The paper examines the foundation of Yoruba cosmological world view in the determination of biomimetic principles that generates environmental harmony through architecture of 'place'. The research is underpinned by the concepts of mimesis, cosmometry and sense of place. It is phenomenological and adopted qualitative methodology. Data gathered through scoped literature and two hour each interview of seven Ifa educational system sages were analyzed using grounded theory to understand mimetic philosophy of Yoruba urbanism. The study revealed that design template reflected in Yoruba city form is a graphic interpretation of "Ifa" earth creation mythology. Yoruba cosmogram is a 16 sided polygon with dominant four cardinal points that occasionally surface as square or it's variant. The study equally identified ' 4 'and ' 16 ' as Yoruba design numerology. Urban 'places' including King's market, quarter spaces, residential units and their court yards are rectangular in forms. Therefore design templates that create "Yoruba atmosphere" are the imitation of her cosmogram super imposed on the landscape where geomantic planning enhances periodic access to earth energy through animism religious belief system. The paper recommends that biomimetic design and planning considerations from the bioregional ecosystem must consciously explore forms and processes reflected by the cosmogram and design numerology. Alignment of such biomimetic design form
\end{abstract}


and planning process must also consider meaningful radiant energy on the landscape to enhance harmonious living where the forces of nature are at equilibrium.

Keywords: mimesis, biomimicry, cosmogram, design numerology, earth energy and harmony.

\section{Introduction}

Global environmental degradation experienced in the twentieth century generated two schools of thoughts on the position of man within the ecosystem. While anthropocentrism submitted that humanity is the centre of existence biocentrism postulates that man is just like any other member of the biotic community (Bidwell and Quinby [1]). Biocentrists believed that the only way for humanity to checkmate the wanton consumption of fixed natural resources is to consciously plan, design, develop and live with nature. It is a call for a systemic approach to design with climate and biophysical variables to create human habitats in harmony with nature. Architects joined biocentrism searching the ecosystem for necessary planning and design solutions to the myriad of problems confronting human settlements. Benyus [2] referred to this art and science as biomimicry which she defined as "a new science that studies nature's models and then imitates or takes inspiration from these designs and processes to solve human problems." Imitating nature is a return to previous design philosophy. Barrell [3] submitted that mimetic theory tremendously influenced the theory of garden and landscape design through the neoclassical axiom that 'art should imitate nature' in pre 1800 theory of painting that paralleled the evolution of landscape theory. The goal of Chinese environmental planning, Feng shui, is to achieve harmony with nature. Traditional Indian architecture, Vaastu, addresses environmental design that is in harmony with the physical and metaphysical forces in nature. Verhagen [4] citing Rifkin observed that "every age has its own unique view of nature, its own interpretation of what the world is all about". That is, world view varies with local people's perception of what is called nature.

Lefferts [5] referring to Buckminster Fuller research works submitted that nature and the universe uses a particular set of energetic relationships that influence the way naturally designed systems are sustainable. In mimetic theory nature mimics the cosmos for sustainability especially using a cosmogram to draw from positive energy. Understanding this cosmic world view is what Lefferts [5] called cosmometry, which he defined as 'the study of the fundamental patterns, structures, processes and principles that are at the foundation of reality and the application of this knowledge towards the design of sustainable and healthy living systems". Such knowledge creates a nexus between cosmos and terrestrial realms through harmonic energy sharing that enhances sustainable design on local scale. This paper examines Yoruba cosmological world view in the determination of architecture of 'place' that promotes harmony with the bioregional landscape. 


\section{2 'Place' in space}

Philosophical urban design literatures attempt to differentiate a 'place' from 'space'. Tuan [6] stated that a 'space' becomes a 'place' when human presence and activity are brought to it. He argued that whereas 'space' is an urban site with defined boundaries appropriate for certain social activities and behaviours, 'place' on the other hand is a spatial locality given meaning by human experiences in it. Accordingly, three components differentiate 'place' from 'space' namely the role of the 'place' within the community, institutional setting of the 'place' and organization that transmits 'place'. Relph [7] noted that 'place' setting can be physical. As physical locations, 'place' becomes centres of felt values as people interact and become acquainted with the landscape [6]. 'Place' is therefore a cultural landscape constituted and perceived by the meanings people attribute to them. 'Place' is not isolation, rather it is part of urban sequence that defined city activities and is influenced by environmental orientations (Haluza-DeLay [8]). Orientation highlights how locals relate to nature in daily, monthly and annual circle. This is in line with Bertschausen [9] perspective on how to bioregionally understand sense of place. He argued that the knowledge of a site is best achieved through the local people that have a true 'sense of the place'. This is because the concept of 'place' addresses man's relationship to his environment especially how such landscape is used over a period of time to create a site specific identity. Such identity, he maintained, emanates from the fusion of spiritual, social and traditional meanings a 'place' generates to the inhabitants. Shortridge [10] referred to this place concept as 'nature in place'. Nature embraces the aesthetic configuration of available flora, rhythmic sounds of water bodies, influence of fauna, and the circular movement of celestial bodies as culturally interpreted. It is a holistic interpretation of 'place' as a state of harmony established through interactions of biophysical attributes, human activities and experience underlain by historic happenings Ndubisi [11]. Experience rather than meaning in its simplest form provides rooms to accommodate mythology and instinctual thinking in the harmonic configuration of place.

\section{1 'Place' and environmental harmony}

'Place' is therefore a holistic setting for local people, nature, and built environment generating unique experience through reciprocal energy exchange that promotes liveability. The relationship is actually a biophilia effect (Bradley [12]). Biophilia reveals the inner desire of man to associate with natural systems and processes that possess healing capabilities and enhance liability. Healing in this paper is not process of curing, but achieving a state of equilibrium between man and nature (Stark [13]). Achieving harmony in built environment is what Clark et al. [14] called urban spiritualism. The ultimate goal of urban spiritualism is to achieve wholeness with nature through a continuous flow of interactions between values and city form. Wholeness on ecosystem level looks at the total component of natural area in biomimicry concept (Benyus [2]). 
Biomimetic principles harmoniously link the entire natural world to the people in a specific 'place' affecting man's body, soul and spirit. (Benyus [2] and Bradley [12]) referred to this harmony as biophilic environmental design consideration. It is a reminiscent of holographic thinking 'that every manifestation of reality is a reflection of the larger totality of existence and that the whole is contained in the part and vice versa' [13]. Clark et al. [14] noted that relating the form and function of a city, as an urban ecosystem, to human physical health rested on the platform that man is 'motivated by meaning, purpose and sense of connection to the universe' Designers then explore form, function and process for such biomimetic connection. Klein [15] opined that biomimicry will be more relevant in sustainable environmental design when the interface of people, place, and nature is understood and well coordinated. That is, biomimicry must explore phenomenology to drive sustainability to a higher level. On the platform of phenomenology, Benyus [2] explanation of biomimicry took cognisance of form, process, and ecosystem in improving sustainability paradigm that give meaning to people in a particular place.

In biomimetic design, natural form expresses its surroundings; natural form goes beyond an image-based encounter to accommodate use-based; and potentially reflect natural processes. Imitating form in 'place' design must phenomenologically understand its ability to modify physical elements that generate negative impact and most importantly shape the social and spiritual aspect of the people. Therefore natural forms are not only biological but also cosmic. It is in line with Akkerman [16] view that "the cerebral theme in the layout of planned towns since antiquity has often reflected the image of cosmic harmony and perfection, unfolding in various notions of the Ideal City". Religious belief in cosmic harmony conceptualised cities, open spaces, buildings, and sculptures in geometrical forms. Imitating nature meant conceptualization of Platonic forms. Lane [17] noted that Plato's philosophy of form states that reality consists of two realms. First, there is the physical world the material dimension that responds to human five senses. And second, there is a world made of eternal perfect "forms". This theory maintained that works of art should imitate the forms in nature where nature embraces planetary systems. Becker and Hagens [18] confirmed that Plato theorized forms are tetrahedron (4 sides), the hexahedron or cube (6 sides), the octahedron ( 8 sides), the dodecahedron (12 sides) and the icosahedron (20 sides). Culturally interpreted cosmic forms influence the prevalent architecture of place where place may be entire human settlement or component parts. Sprajc [19] noted that Maya architecture and urbanism reflects her cosmological concepts. Such influences entail conforming humanly designed structure in harmony with the structure of the universe. Malayeri [20] reference to Nikola Tesla's submission that "one day man will connect his apparatus to the very wheel work of the universe .... and the very forces that motivate the planets in their orbits and cause them to rotate will rotate his own machinery" bears witness to the importance of mimetic thinking in design works. Imitating cosmic forms and process is centred on harmonizing human creation with nature's creation on planetary platform with 
the singular goal that man may enjoy the order and harmony in universe. On site planning scale, MacLean [21] classifies such design as organic architecture.

\subsection{Architecture of 'place'}

The proponents of organic architecture see building as living organism responding to gaseous, liquid, solid materials and energies input and output with the ecosystem. Energies exchange in organically built structures include "subtle grid of electromagnetic patterns and vortices, terrestrial and cosmic energies, where the building serves as a node or satellite like receptor, to focus and enhance these energies" [21]. According to Okedele and Adejumo [22] earth energies that flow within planetary grids influences human mind. Newman [23] observed that major world megalithic structures, stone circles, pyramids, dolmens, volcanic spots, fault lines and ancient mounds that attract man over the ages were located on these grids. The modern concept of planetary grid operates on Hermetic philosophy (Leviton and Coons [24]). One of the principles of Hermitic teachings states that "As above, so below". Planet earth is a mirror image of heaven. Therefore what exist in material world has already existed in the immaterial world. The earth surface is therefore laid out according to a cosmic scheme (Becker and Hagens [18]). Poynder [25] study of Carrowmore dolmen revealed that Stone Age man burial ground is located at the centre of the earth star. He claimed that the practice of locating burial ground at sacred high earth points were carried forward through time into Bronze age, Iron age and subsequently into the layout of Celtic churches that were later rebuilt as cathedrals. Typical example is Salisbury Cathedral built in 1220 AD [25]. His study shows that the site planning of the cathedral aligns with the earth star permitting the Bishop to meet the spiritual needs of the congregation through the positive life force. The study revealed that the centre of the earth star is where the church altar is located. Every year over 500,000 faithful visit Salisbury Cathedral from all over the world not because of its medieval architectural aesthetics but because of efficacy of prayers offered [25]. This is environmental harmony and the architecture of place.

Cultural architectural practices in oriental nations are historically based on achieving environmental harmony. Cheun-Yan [26] observed that Chinese gardens and similar urban open space works are cosmic diagrams, revealing an ancient view of the world and of man's place in it. The Chinese geosophic thinking is that planet earth is believed to behave like living organism with veins, represented by rivers and sub terrainious water courses, and centres of energy (chi). Vãstu Shãstra, as fundamental India design with nature, focused on effect of planning on the environment and people bearing in mind radiations from sun, other planets and various earth bio forces (Naik [27]). Like other aboriginal nature designs, it is more than achieving aesthetics and functionality in buildings. The primary goal is spatial configuration that generates positive influence on the happiness, prosperity and well being of the residents [27]. Vãstu architecture is about emulating the attributes of the cosmic space, bringing positive cosmic essence into homes and creating harmonious living environment where the forces of nature are at equilibrium. The buildings fall within MacLean's [21] 
definition of organic architecture. Such architecture irrespective of geographical location is influenced by bioregional landscape, culture, historic background and prevailing technological orientations. These variables collectively define design forms, orientation alignment with natural inputs that generate wholeness. Organic architecture does not stop at biophilic or biomorphic designed form but incorporate natural essence that keep the ecosystem in equilibrium. This research examines cosmological worldview of Yoruba urbanism, to understand the design form, orientation and geomantic system that influence her architecture of 'place'.

\section{Study area}

Yoruba nation lies between longitudes $1^{\circ} 25^{\prime} \mathrm{E}$ and $6^{\circ} 45^{\prime} \mathrm{E}$; Latitudes $5^{\circ} 55^{\prime} \mathrm{N}$ and $9^{\circ} 10^{\prime} \mathrm{N}$ above the equator. In Nigeria, Yoruba nation inhabit the south western geopolitical region (Fig. 1). It is fully made up of five federating units of Nigeria including Lagos, Ogun, Oyo, Osun and Ondo states. Parts of Kwara, Kogi and Edo states are inclusive. All classic Yoruba cities share the same form (Obateru [28]). There seemed to be a distinct traditional school of planning with unwritten urban design manual. Fatunbi [29] revealed that Yoruba philosophy of life including urbanism is encoded in Ifa educational system.

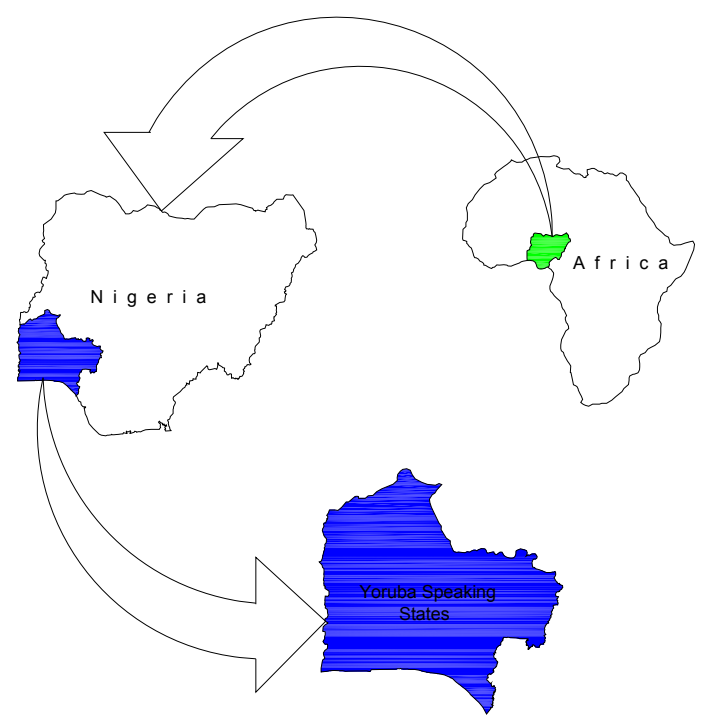

Figure 1: Yoruba cosmological world view foundation (Okedele and Adejumo [22]). 


\section{Methodology}

This research is interpretive in nature. It is in two stages namely desktop study to understand the philosophy of Yoruba urbanism and her central public space; and two hour semi structured interview of Ifa sages spread across south western geopolitical zone - the Yoruba States in Nigeria. The paper recognised previous research works on geosophic perspective of Yoruba urbanism as authentic secondary information [22]. The desk top study took into consideration Yoruba design world view especially the cosmogram relative to her geosophy. The research is phenomenological and adopted qualitative methodology. Data gathered through scoped literature on Yoruba urbanism and two hour each interview of seven Ifa sages were analyzed using grounded theory. Each scoped literature was subjected to open coding to derive incidents, codes, concepts and categories on the phenomenon. The open coding proceeded in parallel, treating each literature as confirmation or further development of results from earlier one. The second group of textual data was semi structured interviews of sages and was analysed likewise.

\section{Findings and discussion}

The study revealed that Yoruba urbanism is a reflection of her cosmological worldview as expresses in Ifa mythology of earth creation .The mythology states that 16 spirit beings (deities) were dispatched by God (Olodumare) to recreate planet earth after the big flood. The King (Oba) operates from the position of Supreme Being "Olodumare" while quarter chiefs' role modelled 16 divinities (Fig. 2). This is confirmation of previous studies that most Yoruba cities have 17

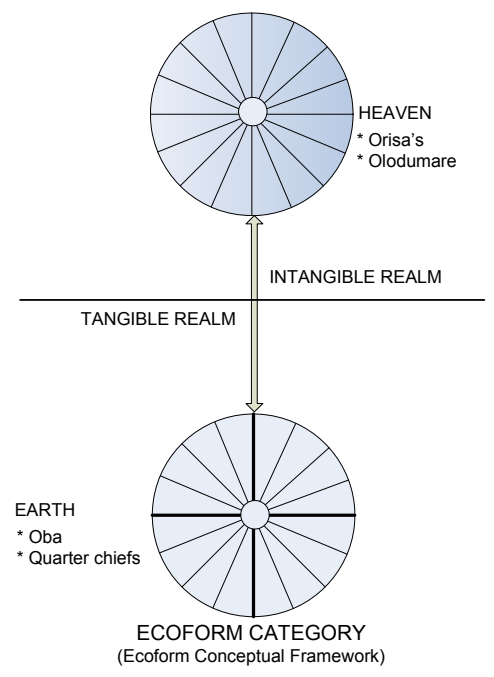

Figure 2: $\quad$ Yoruba cosmological world view [22]. 
traditional quarters [28]. Each quarter is an agglomeration of compounds. Four of the sixteen deities (orisas) are primordial divinities and often referred to as major gods (orisas). Included in this category are "Orisa-nla" (the deity that lead 15 others for earth re creation exercise); "Ifa" (deity of divination), 'Jakuta' (god of thunder and in charge of climate) and 'Lakaiye' (Yoruba deity in charge of technology). The remaining 12 constitute minor deities.

Analysis of scoped literature and Ifa sages identify direct influence of cosmological world view on the Yoruba design template, design numerology, governance and city symbol (Fig. 3).

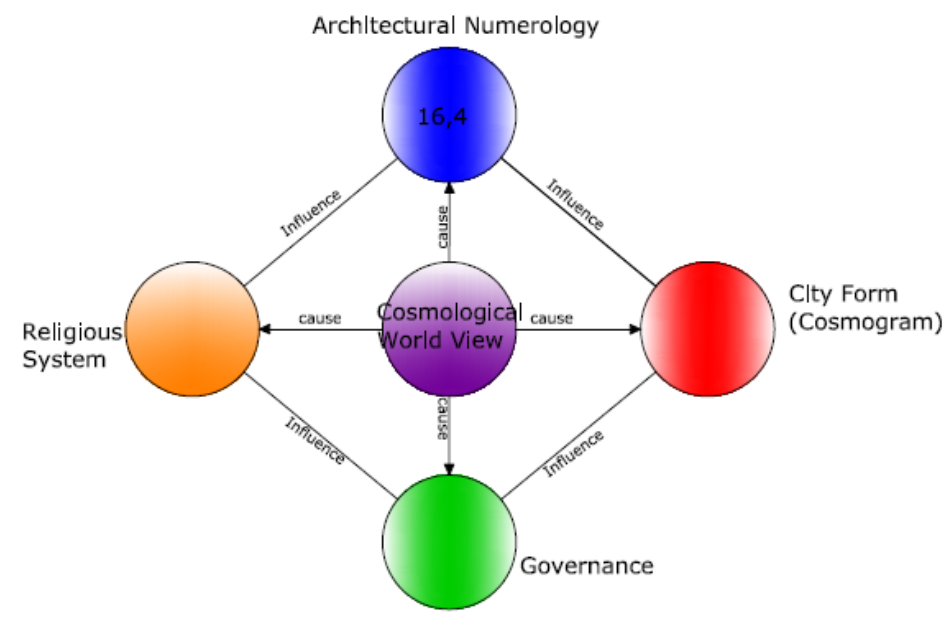

Figure 3: $\quad$ Yoruba cosmological world view influence.

\subsection{Cosmogram}

The cities were platted on cosmological philosophy that evolved from her mythology of earth creation [29]. In Yoruba understanding of heaven (intangible realm) there are ' 16 prominent 'orisas' on the beck and call of 'Olodumare'. On the earth (material realm) there are also 16 'Oloye' (Chiefs) answerable to the king (Oba). The principle is planet earth (Ikole aye) must be a replica of heaven (Ikole orun) where God (Olodumare) sends 16 divinities to create earth. Since Olodumare' (God) is the monarch of the spiritual realm and the universe then the Oba (King) is the monarch in this realm of matter. On aerial basis, the four cardinal primary roads radiate from the royal core to divide the city into four theoretical sectors. Each of the sectors is then further divided in to four minor sectors to arrive at sixteen quarters. The influence of cosmological world view on Yoruba urbanism manifested in the three environmental harmony conscious properties namely cosmic urban form, design numerology and cardinal orientation. Cosmic urban form referred to the 16 sided polygons influenced by the 16 divinities in Ifa earth creation mythology. In addition to cosmic form is the square that corresponds to the cardinal points often attached to primordial 
deities (Fig. 4). Barrel [3] noted that Platonic forms created basis upon which 1800 garden art and landscape design developed including sphere, the circle, the cube and the square.

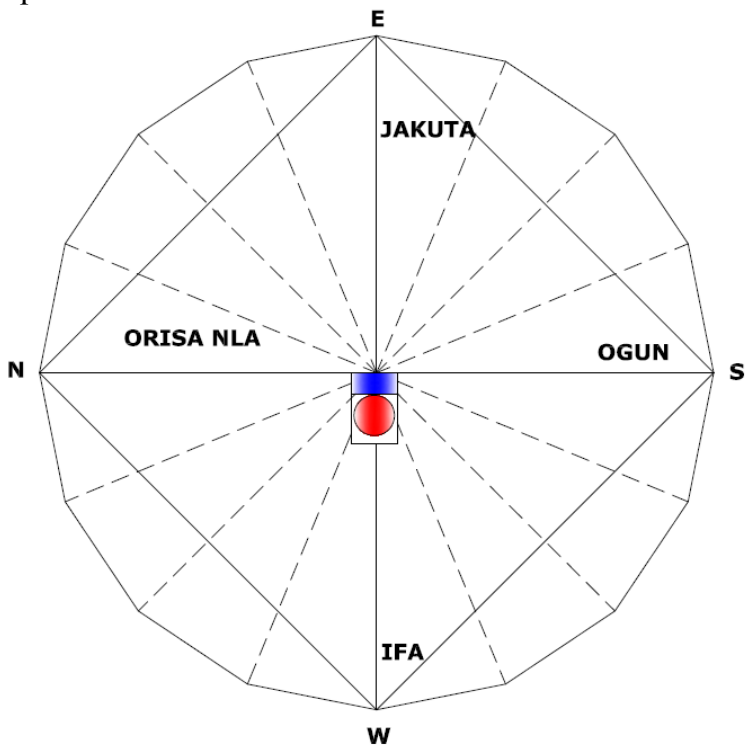

Figure 4: $\quad$ Yoruba cosmogram and the twin land use city core.

The forms were derived from tetrahedron (4 sides), the hexahedron or cube (6 sides), the octahedron ( 8 sides), the dodecahedron (12 sides) and the icosahedron (20 sides) (Becker and Hagens [18]). In geometry, a four-sided square represents the earth, while a circle represents heaven, eternity, and the realm of spirit Jones [30]. For the Yoruba people the forms that carry harmonious essence are 4 and 16 sided or their multiples. Four sided squares and its variables (rectangle) represent the earth and is responsible for one of the metaphors associated with four cardinal points which states that 'planet earth has four points' (Igun merin ni aye ni). Yoruba world view associates ' 4 'with productive unity driven by male and female energies in a state of equilibrium (Ologundudu [31]). Female energy refers to the earth energy prevalent in the biospheric ecosystem while male energy is the cosmic male energy infused from other members of the universe to this realm of matter. Dwelling units are configured as squares or rectangles with a square court yard to draw down this energy. Agglomeration of dwelling units constitute a compound with a bigger four sided courtyard.

\subsection{Religious system}

Religion plays dominant roles in the socio cultural behaviour of man especially his relationship to cosmic influences. Yoruba people belief system is polytheist. It is nature based communing with the supreme 'Olodumare' (God) through 'orisas' (divinities). Besides the 16 earth creation 'orisas' contingents there are 
several others attached to hills, rivers and other inanimate objects. Yoruba geomantic planning identifies the city core as major city dome where earth energy is assessed. Most of the national Yoruba deities are located within the core land uses especially the palace and the king's market. Therefore the city core is a major temple full of religious activities throughout the year. Since the dome in planetary grid operate as earth energy junction box, the Yoruba belief system refers to the city core as major city dome junction that serves as portal to heaven. Hence the symbol of the city is 'Orita "translated as junction. It is a spiritual interchange where men and divinities commune. City core as the prime dome (orita) communicate vertically to heaven and also horizontally to other minor domes in the quarters. So the city core becomes a panoramic and spiritual vantage position for king/priest to exercise his authority over the city state.

\subsection{Design numerology}

"16 and 4" constitute design numerology in Yoruba daily living and art works. Ifa sages interview further revealed the use of ' 16 ' and ' 4 ' in divination system. There are 16 major 'Ifa Odus' [31]. Geometry in architecture plays very important roles in the determinant of building forms and sum total spatial configuration. Architectural art are in two planes of existence namely conceptual and tangible realms. While conceptual art features in architectonic space definitions, the material plane manifests in construction stage. Both realms use geometry as expressional tools. Modern architecture relies upon sacred geometry for culturally sustainable contemporary designs. Sacred numerology is often reserved primarily for the expression, instruction, and codification of metaphysical concepts. Jones [30] observed that in Hebrew language letters are used as numbers, and the letters are also words and concepts that can be used either literally or symbolically. For Christos- Judaism numbers 8 and 50 represent new beginning and jubilee respectively. In his reflection on Alhambra palaces cultural expression, Darr [32] highlighted the importance of numerology in Islamic architecture. He observed the repeated use of the word 'barakah' in hundreds of places throughout the palaces. Barakah' means manifestation of "blessing" or "divine grace." and is coded as the pinecone, acorn, leaf sprout and seashell as naturalistic emblems - an ancient pre Islamic symbol of bounty and fertility as well as good fortune. Darr [32] submitted that 'mystical and cosmological symbolism, whether found in literature, art, or architecture, created a context for understanding and attuning oneself to the spiritual world'. The use of numerology in Yoruba design and planning arts manifest in city layout and cosmological symbolism in building design. Urban places including King's market, quarter spaces are rectangular in forms. Each city quarter is an agglomeration of compounds made up of densely built up dwelling units. The compounds and residential buildings are rectangular with four sided court yards. King's market is rectangular in form and serves as major city node for commerce, religious and cultural activities. Architecture of place on city, sector, and individual building scale must be conscious of Yoruba design numerology. Ecological design driven by biomimetic framework to create harmonious 
environment, need to explore the contextual bioregion for natural forms and processes based on design numerology and its variants for cultural acceptability.

\subsection{Earth philosophy}

In traditional Yoruba religion, the earth is treated as a goddess. Famule [33] identified Ogboni as the Yoruba earth goddess. Earth is believed to generate both positive and negative energy (ase). Therefore before any development Ifa priest must divine to ascertain whether the parcel of land is an ideal location for proposed land use; whether the in dwelling beings will cooperate with human on the proposed land use; and to understand the nature of earth energy. The end product is to locate most auspicious land geomantically. The Yoruba wisdom of living harmoniously with other structural members of the biospheric ecosystem revolves around geomantic planning. Geomantic planning searches the landscape for energy confluence in Yoruba world view as ideal urban nodal space where man and nature is in harmony.

\section{Conclusions and recommendations}

Detail ecosystem study and observation of local people's phenomenological experience on built environment are interrelated approaches to understanding harmony in human settlements [1]. While the former looks at contextual ecosystem for useful forms and processes to solve built environment problems the later understudies rooted forms and processes in aboriginal places that sustained the people. It is introduction of culture in biomimetic frame work. Nelson et al. [34] suggested exploration of preliterate and preindustrial cosmological world view to fully understand the input of culture in biomimetic framework. It is hinged on the understanding that driving astronomical knowledge and local view of the universe played dominant roles in the spatial configuration of ancient cultural landscapes. The beliefs composing the worldview were incorporated into the political ideology of rulers, who as 'mangod' was held responsible for the proper functioning of the universe, alignment of civic and ceremonial architecture and lay out of city elements according to cosmic order and form [34]. The study revealed that design template reflected in Yoruba city form is a graphical interpretation of "Ifa" earth creation mythology. Yoruba cosmogram is a 16 sided polygon with dominant four cardinal points that occasionally surface as square or it's variant. Design patterns in its entire ramification including textile, industrial, urban and building intuitively follow this form. The study equally identified '4'and ' 16 ' as Yoruba design numerology. Urban 'places' including King's market, quarter spaces, residential units and their court yards are rectangular in forms. The design template did not accommodate scientific modernism 'form follow function' concept. Rather forms that create "Yoruba atmosphere" are the imitation of her cosmogram super imposed on the landscape where geomantic planning enhances periodic access to earth energy through animism religious belief system. On this note 
environmental harmony conscious architecture of 'place' in Yoruba urbanism must explore the following:

* Biomimetic designs that consciously explore the contextual ecosystem for forms in the mode of mimetic cosmogram and design numerology. Such architectural form focuses on emulating the attributes of Yoruba cultural cosmic space.

* Biomimetic forms must consider alignment desired with radiant energy on the landscape that creates harmonious living where the forces of nature are at equilibrium. It is connecting houses and manmade design works directly to cosmic scheme to checkmate the production of excess carbon dioxide from hydrocarbon driven energy source [20]. Such buildings or design works constitute place architecture influenced by bioregional landscape, culture, historic background and prevailing technological orientations. These variables collectively define design forms, orientation alignment with natural inputs that generate much desired wholeness.

Environmental harmony of 'place' architecture must then be understood on two symbiotic levels. The first is cosmic harmony which is a harmony of material and immaterial with the singular goal of oneness with planetary ecosystem. It is a mimetic design and planning using cosmic forms in city and architectural works to draw culturally accepted cosmic energy (spiritual) necessary for productive living. The second is a harmony with bioregional ecosystem under the influence of earth energy that criss-crosses the landscape. This is biopsychic harmony - the domain of biomimicry. Architecture of place then biomimetically searches contextual ecosystem for culturally meaningful cosmic forms and processes that connect human design with cosmic scheme to make sustainability relevant on local scale

\section{References}

[1] Bidwell, K., and Quinby, P.A., Sustainability and the Value of Ancient Forest Landscapes. Ancient Forest Exploration \& Research .RR \#4, Powassan, Ontario POH 1ZO. Canada. Report No 5, 1994. Retrieved from www.ancientforest.org/rr5.html

[2] Benyus, J. M., Biomimicry, Innovation Inspired by Nature. William Morrow: New York. 1997.

[3] Barrel, J., The Political Theory of Painting from Reynolds Hazlitt. Yale Press University: Yale. 1986.

[4] Verhagen, F.C., Worldviews and Metaphors in the Human-Nature Relationship: An Ecolinguistic Exploration through the Ages. Journal of Language \& Ecology. 2 (3), 2008. Retrieved from www.globalepe.org

[5] Lefferts, M., Cosmometry: Embracing a New Paradigm of Understanding and Design, 2007. Retrieved from http://www.cosmometry.net/pdf

[6] Tuan, Y.F., Space and Place: The Perspective of Experience. University of Minnesota Press. Minneapolis, 1977.

[7] Relph, E., Place and Placelessness. Peon Books: London, 1976 
[8] Haluza-DeLay, R., Caring for place? Possibilities for a compassionate sense of place among environmentalists. In Developing a Compassionate Sense of Place: Environmental and social Conscientization in Environmental Organizations, 2006. Retrieved from randy.haluzadelay@kingsu.ca

[9] Bertschausen, R., On Time and Place: A Philosophy of Place. Fox Valley Unitarian Fellowship. 1995. Retrieved from www. essaytree.com/ philosophy/.

[10] Shortridge R., Ingredient of Place. Journal of Urban Land Institute, 61(7), pp36- 41, 2002.

[11] Ndubisi, F., Ecological Planning: A Historical and Comparative Synthesis. Johns Hopkins University Press, London, 2002.

[12] Bradley, S., Biophilia Effect: Improving Your Design with Nature. 2010. Retrieved from www.vanseodesign.com/web-design/biophilia-effect

[13] Stark, A., Buildings that Heal: The Use of Energetic Criteria in the Design of Healing Environments. Creating Outstanding Environments. London, (2009). . www.alexstark.com/pdfs/Buildings\%20that $\% 20 \mathrm{Heal}$

[14] Clark, L., Holland, M.; Karakas, J.; Craig, K.;Moen, M., Components of a Spiritual Urbanism. The International Journal of Healing and Caring. 10 (3), 2010). Retrieved from http://www.ijhc.org

[15] Klein, S., A Phenomenological Interpretation of Biomimicry and Its Potential Value for Sustainable Design. (Masters of Science in Architecture Dissertation), 2009. Retrieved from http://krex.k-state.edu/dspace/ handle/2097/1478

[16] Akkerman, A., Harmonies of Urban Design and Discords of City-form: Urban Aesthetics in the Rise of Western Civilization. Journal of Urban Design, 5(3), pp.267- 290, 2000.

[17] Lane, M., Plato: The Republic. Penguin Books Limited Translated by Desmond Lee. London, 2007.

[18] Becker, W. and Hagens, B., The Planetary Grid: A New Synthesis. AntiGravity and the World Grid, eds., Childress, D.A., Adventures Unlimited Press: Kempto pp.27-50, 1999.

[19] Sprajc, I., Astronomical and Cosmological Aspects of Maya Architecture and Urbanism. Cosmology across Cultures ASP Conference Series, 409 eds. J. A., Belmonte, J. A., Prada F., and Alberdi, A., 2009.

[20] Malayeri, S., Biomimicry in Buildings. (Masters of Science in Architecture Dissertation), 2009. Retrieved from http://11thhouraction.com/ taxonomy/term $/ 45$

[21] MacLean, H.P., Organic Architecture: Sustainability and Geomancy as One Timeless Architecture. Boston, 1997. Retrieved from http:// Timearch.com

[22] Okedele, N. and Adejumo, T., Geosophic Perspective in Yoruba Urbanism. Proc. of West Africa Built Environment Research (WABER) Conference 2011, eds. S. Layea, R. Leiringer and W. Hugh, Accra, Ghana. pp.517-527.

[23] Newman, H., Earth Grids - The Secret Patterns of Gaia's Sacred Sites. Wooden Books, 2008. Retrieved from: http://www.woodenbooks.com/. 
[24] Leviton, R., and Coons R. (1999). Leylines and the Meaning of Adam. Anti - Gravity and the World Grid, eds., Childress, D.A., Adventures Unlimited Press: Kempto pp.27-50, 1999.

[25] Poynder, M. The Lost Magic of Christianity: Early Essene Connections, Green Magic BCM Inspire: London, 2000.

[26] Chuen-Yan D.L. (1974) A Feng Shui Model as Allocation Index. In Annals of the Association of American Geographers, (64) 4: 506-513.

[27] Naik, A. Vãstu Architecture, Harmonious Habitat and National Growth. In Conference Proceeding 5th National Convention and Exposition "Housing for All". NAREDCO, India, 2005. Retrieved from www.vastusindhu.com

[28] Obateru, O., The Yoruba City in History: $11^{\text {th }}$ Century to the Present: Penthouse Publications, Ibadan, Nigeria 2006.

[29] Fatunbi A.F., Odu and Ifa Concept of History: The African Perspective. Part IV. Awo Study Center, 2004. Retrieved from http:www.Scribd.com/doc/47350772/odu-ifa-concept of history

[30] Jones, S.E., The Biblical Meaning of Numbers from One to Forty. God's Kingdom Ministries, 2008. $\quad$ Retrieved from www.Godskingdomministries.org

[31] Ologundudu, D., The Cradle of Yoruba Culture: Center for Spoken Words/Institute of Yoruba Culture Yoruba Culture, New York, 2008.

[32] Darr, R.A.H. The Palace of Blessing and Grace Discovering Spiritual Symbolism in the Court of Lions at the Alhambra in Spain, 2006. Retrieved from www.scribd.com/.../Discovering-Spiritual-Symbolism-in-the-

[33] Famule, O.F., Art and Spirituality: The Ijumu Northeastern -Yoruba Egúngún. (Doctoral Dissertation), $2005 . \quad$ Retrieved from etd.library.arizona.edu/etd/

[34] Nelson, B.N.; Lekson S.H.; Šprajc, I; Sassaman K.E., Shaping Space: Built Space, Landscape, and Cosmology in Four Regions. Prepared by the Built Space/Environment Working Group for the Santa Fe Institute Workshop on "Cosmology \& Society in the Ancient Amerindian World. 2010 Retrieved from www.santafe.edu/media/workingpapers 